rem ser muito objetivas, descrevem fatos. Então, eu brinquei com a Bader: "Bader, de hoje em diante, não se entrevista mais ninguém sem perguntar 'o que você sentiu?"' Ela é que observou a diferença entre ela conversando com as faveladas, elas narrando para a Bader o que tinha ocorrido, e elas entre si, comentando, e comentando as emoções sentidas. E jamais tinham dito para a Bader. Quando você entrevista alguém, as pessoas não falam o que sentem, elas querem narrar os fatos tal como ocorreram. Aquilo que eu estava falando para o Marlito do sonho. Os nossos sonhos, em geral, são emoções reprimidas, segundo o Freud. Mas o índio não tem essa repressão toda. Então, o sonho tem um outro poder na vida do índio, não de soltar o inconsciente, mas de comunicação. E nós reprimimos os nossos sonhos...

Estas indagações levaram Sílvia a pensar num projeto de pesquisa com objetivo de analisar as emoções em culturas indígenas, trabalho que foi iniciado em 2003, com financiamento da Fundação de Amparo à Pesquisa do Estado de São Paulo (FAPESP). Em 2005, foi concedida extensão, para dar conta do desejo de Sílvia de pesquisar os sonhos dos Xavante. Atualmente, a professora Bader Sawaia coordena esse trabalho, com minha colaboração e a de Marlito de Sousa Lima, que expõe, em seguida, o processo de realização do projeto.

Maria Helena de Mendonça Coelho é psicóloga clínica; participante do núcleo NEXIN, (Exclusão-Inclusão) da Pontifícia Universidade Católica de São Paulo (PUC-SP). Endereço para correspondência: PUC-SP, Rua Monte Alegre, 984, São Paulo, SP, 05014-001. mariahcoelho@terra.com.br

\title{
CONVERSAS AO PÉ DA PESQUISA
}

\section{Marlito de Sousa Lima \\ Pontifícia Universidade Católica de São Paulo, São Paulo, Brasil}

Quando eu fazia o mestrado (ainda era um núcleo com a Sílvia e a Bader junto) a Sílvia começou a se interessar pela questão da emoção, questão que vinha aparecendo nas dissertações e teses de seus orientandos, mas que não cabia dentro da arquitetura metodológica e conceitual que o núcleo usava. Aí começou-se a discutir como tratar da afetividade. Nesse momento, já havia um debate entre os membros do núcleo sobre o marxismo. Eu criticava a versão que alguns defendiam, que chamava de meio vulgar, porque a determinação econômica aparecia em e sobre tudo, principalmente em torno do conceito de trabalho. Não se distinguia trabalho de atividade. Eu falava que isso era protestantismo, uma ética do trabalho como redenção do homem decaído diante de Deus. Sílvia dava muita importância para essas discussões porque era justamente o reducionismo e o maniqueísmo que ela queria evitar.

Fizemos discussões sobre o sonho, e eu relatei como o Xavante conta o sonho, uma narrativa sem análise, porque o sonho, para eles, é o relato de uma realidade que não se distingue dos fatos (do modo que nós distinguimos), dos acontecimentos da vida desperta. O sonho xavante tem uma ligação com o que chamamos vulgarmente de realidade, que nós, ocidentais, não conhecemos. Para o Xavante a interpretação é aquilo que enfraquece a civilização, porque toda vez que você interpreta, é possível que outra pessoa interprete o que você diz. O Xavante sempre fala assim: "o que um civilizado diz, nunca é exatamente aquilo o que ele diz. Ele sempre tem que interpretar". E essa interpretação que é a desgraça da nossa cultura, segundo eles. Ao contrário de nós, que recorremos à razão, o que o eles chamam hossarade (se localizaria na testa), a narrativa xavante é relacionada à região do peito e da barriga, onde eles sentem as emoções. Eles falam que a razão da civilização separa o que é certo e errado, o verdadeiro e falso, o bem e o mal, e, ao fazer isso, o civilizado fica inseguro sobre o que fazer, então ele não tem decisão.

Foi com essa questão de como as emoções apareciam na narração, nos rituais e nos mitos indígenas, que a Sílvia começou a se interessar mais profundamente pelo estudo dessas culturas. E, como lembra Bader, Sílvia observou que o Vigotsky também procurava estudar o habitante da Sibéria, que seria o equivalente ao nosso indígena, com a intenção de demonstrar as determinações do social no comportamento dos indivíduos.

O que impressionava também a Sílvia eram os relatos dos rituais. No ritual de iniciação Xavante, o iniciado é colocado num círculo, de uns 800 guerreiros cantando, batendo com o pé, o que produz uma vibração imensa no chão, no ar. E o que mais impressiona é que, de re- 
pente, alguém no círculo dá um grito e todos fazem o movimento inverso. Uma vez, quando entrei num desses círculos fiquei preocupado porque queria saber quando era a minha hora de gritar. Que momento era. E os velhos falaram que não tinha um momento certo. Você entra no círculo e canta, uma hora você vai gritar. E eu acabei perdendo essa noção de hora, de tempo, quando entrei no círculo. Quando eu gritei, todo mundo voltou porque existe uma sincronia perfeita. E, dentro desses círculos de iniciação, tem grupos que dançam uma dança, do ponto de vista visual, bastante agressiva, para pisar no pé do iniciado. O grupo de guerreiros vem dançando para pisar no seu pé e mirando o olhar no iniciado. E dentro desse círculo você começa a sentir emoções que eu, particularmente, nunca tinha experimentado. Foi aí que entendi que esse tipo de iniciação era feito para que essas emoções viessem à tona. A Sílvia ficava impressionada com esse tipo de narração. O reconhecimento dessas emoções vai ser importante para o guerreiro, na cultura de guerra. É o guerreiro que conhece as emoções, conhece profundamente essas emoções. Não é uma catarse. Nós pensamos a partir do indivíduo, na categoria do indivíduo contra o coletivo. Nas comunidades xavantes, você é indivíduo na medida em que você é inserido no coletivo, então sua individualidade é reconhecida e afirmada na medida em que você está inserido profundamente no coletivo. O guerreiro é aquele que conhece o seu grupo e experimenta essas emoções coletivas. Porque não é bem um compartilhar de emoções. Nesses rituais, há um reconhecimento das emoções que cada pessoa tem. É como se o canto e a dança fossem uma sineta para despertar isso. Todo ritual indígena é desconhecido para o iniciante, ele não domina o que vai acontecer, porque é segredo do grupo que já passou por aquilo. O iniciado é aquele que se inicia no segredo daquele grupo. Aquele ritual é uma experiência desconhecida; é uma experiência coletiva dos grupos de idade, que são inseridos numa parte do grande ritual, onde experimentam essas emoções que o ritual desperta, o que, para o Xavante, é um poder, o poder que o indivíduo tem dessa inserção e da participação no ritual.

Partindo dessas informações, Sílvia pensava como a civilização acabou interpretando ao contrário a dialética indivíduo x sociedade, nas comunidades indígenas, negando, por exemplo, que o Xavante, pudesse assumir uma individualidade, já que estaria diluído no grupo. Minha experiência com os indígenas coincidia com o que Sílvia pensava, pois o Xavante é reconhecido como indivíduo na medida em que se insere no coletivo.

Toda cultura do ritual é levar o sujeito a um extremo psicológico e físico (muito tempo sem comer nem beber, cansado), porque nessa situação ele pode ter contato com os antepassados, uma vez que ele é semelhante a eles. Para descrever a importância da semelhança para Sílvia recorri ao conceito de Walter Benjamim: assemelhar como a grande busca da identidade. Os antepassados como a fonte da identidade grupal e individual.

Posteriormente, na pesquisa, nós começamos a ver a ligação de identidade entre o mito e o ritual; buscamos entender como o ritual realiza determinados mitos, o que significa que ele é a atualização do tempo mítico.

A Sílvia era muito intuitiva. Ela não ia a campo por um respeito imenso aos índios. Dizia que lá ela iria ser completamente inútil. Não conhecia a cultura, não sabia falar a língua, iria virar um peso, dizia ela. Sílvia tinha uma sensibilidade imensa, que lhe possibilitava a capacidade de definir problemas cruciais da pesquisa.

$\mathrm{O}$ interesse dela pelas culturas indígenas começou pelo sonho, porque no sonho aparecem mais fortemente as emoções. Ela ficou interessada em compreender um ritual ligado ao sonho, em que, todas as tardes, em determinadas épocas, os wapté (adolescentes), afastados dos demais moradores da aldeia durante cinco anos, escolhiam um sonhador, amarravam um chocalho na perna dele, e entravam na aldeia à tarde. Todo mundo se tranca $\mathrm{e}$ eles vão de casa em casa, em cada porta, cantar o sonho. Esse sonho não é narrado usando uma linguagem do cotidiano, é um som que o cantador, que é o sonhador, emite. Ele faz uma música que ele recebeu com o sonho, e quem está no interior da casa comunga com aquele sonho, só pelo canto, há uma emoção entre o sonhador e quem está dentro de casa. Era esse tipo de comunicação, que não está dado por uma linguagem discursiva, que chamava a atenção da Sílvia. É emoção passada pelo canto e pela dança. Quem está dentro de casa entende e chora. Uma comunicação que passa só pelo som, daquilo que o outro sentiu quando sonhou. Como eles estão separados da família, não podem encontrar o pai e a mãe. É como eles não existissem corporalmente. Porque você chega numa etapa da vida que precisa conquistar o corpo de adulto. Não pode falar, não pode escutar, nem se pratica a sexualidade nesse período. Essas quatro coisas são conquistas do iniciado. Ele tem que conquistar isso. Um jeito que eles têm de se comunicar com a família, com a mãe é através desses cantos. E aí se produz uma emoção imensa em quem está dentro de casa. A mulher pode chorar ouvindo esse canto, mas o homem não pode chorar em público ao ouvi-lo. Normalmente os homens se emocionam lembrando que eles também foram wapté, iniciados. É um ritual só para os homens. Eles não passam idéias, só sentimentos.

Uma qualidade fantástica da pesquisadora Sílvia é que ela via dialética em absolutamente tudo. Eu acho que sua sensibilidade vinha dessa capacidade de intuir uma totalidade que estava atrás de cada coisa particular que a gente falava. Considero que essa capacidade de 
pensar dialeticamente era a base de sua intuição. Ela sempre falava que o índio tem uma capacidade dialética para bem além de qualquer civilizado. $\mathrm{E}$ eu, às vezes, ficava pensando se a capacidade estava nela de ver, de perceber, de ser sensível a esses detalhes.

A Sílvia, em um congresso, teve contato com índios latino-americanos, mexicanos, que estavam indo para a universidade para poder recuperar a cultura deles, a língua, os costumes... Ela ficou encantada com essa idéia, e pensou que na primeira parte do nosso projeto a gente exploraria os relatos dos mitos, numa segunda juntaria mito e ritual, e a terceira etapa seria mais internacional. Ela queira trazer índios para cá e levar Xavante para lá. Ela sonhava o projeto como uma coisa imensa, para toda a América Latina; queria fazer o contato entre esses jovens que ela encontrou na Universidade com índios do Brasil. Sílvia nunca pensava num problema localizado no Brasil, sempre pensava em torno da América Latina, buscando estratégias para o congraçamento dentro da psicologia social. Ela achava que nós poderíamos ter como retorno, neste projeto, uma possibilidade de autocrítica. Não iríamos ensinar nada para os índios, mas, a partir deles, poderíamos fazer uma autocrítica da civilização e da psicologia, um confronto com aquilo que a cultura reprimiu na arquitetura da civilização. A busca era essa. E por isso ela tinha um respeito profundo, por exemplo, pelos ritmos que uma cultura indígena acaba impondo à gente quando se tenta pesquisá-los. Muita coisa do projeto nós não fazíamos porque o tempo deles acabava atrapalhando o planejamento da pesquisa e vice-versa. Uma das maiores dificuldades neste projeto foi e é o tempo. Tanto que ele já começou num tempo errado. O início do projeto que foi combinado com os Xavante, foi adiado, pois coincidia com o tempo de encontro com velhos que estavam se deslocando de lugares muito distantes e eu não pude ir porque o dinheiro ainda não tinha sido liberado pela agência financiadora. Sílvia respeitava profundamente essa temporalidade. Ela sabia que a diferença no ritmo do tempo atrapalhava tudo, mas corria esse risco.

Essa é a pesquisadora Sílvia - paciente, uma paciência dos sábios, intuitiva, respeitando sempre a dignidade do outro e com uma capacidade enorme de pensar dialeticamente.

Numa visita que nós, pesquisadores do seu último projeto, fizemos à Sílvia, poucos dias antes de sua morte, ela falou sobre os rumos do nosso trabalho e sobre pesquisas futuras que gostaria de realizar, como se soubesse, e sabendo, que tudo está em permanente movimento.

É sempre bom ressaltar a preocupação de Sílvia, até os últimos dias de sua vida, pelos direitos das minorias. Na sua última pesquisa, com os Xavante, ela recomendava, insistentemente, que priorizássemos suas prerroga-tivas de falarem sobre si mesmos, de terem garantido o espaço para se colocarem como sujeitos de sua história.

Marlito de Sousa Lima é filósofo; participante do Núcleo de Estudos Psicossociais da Dialética Exclusão/Inclusão Social (NEXIN) da PUC-SP. Endereço para correspondência: PUC-SP,

Rua Monte Alegre, 984, São Paulo, SP, 05014-001 marlito_de@uol.com.br

\section{Sílvia por Ela Mesma}

Maria Helena de Mendonça Coelha e Marlito de Sousa Lima Recebido: 24/05/07

Aceite final: 14/09/2007

$1^{a}$ revisão: $30 / 07 / 2007$ 